\title{
Oral Zinc Sulfate as Adjuvant Treatment in Children With Nephrolithiasis: a Randomized, Double-Blind, Placebo-Controlled Clinical Trial
}

\author{
Parsa Yousefichaijan,, Ali Cyrus, ${ }^{2}$ Fatemeh Dorreh,, ${ }^{3}$ Mohammad Rafeie, ${ }^{4}$ Mojtaba \\ Sharafkhah, ${ }^{5, *}$ Faryar Frohar, and Fatemeh Safi ${ }^{6}$ \\ ${ }^{1}$ Department of Pediatric Nephrology, School of Medicine, Arak University of Medical Sciences, Arak, IR Iran \\ ${ }^{2}$ Department of Surgery, School of Medicine, Arak University of Medical Sciences, Arak, IR Iran \\ ${ }^{3}$ Department of Pediatrics, School of Medicine, Arak University of Medical Sciences, Arak, IR Iran \\ ${ }_{5}^{4}$ Department of Biostatistics and Epidemiology, School of Medicine, Arak University of Medical Sciences, Arak, IR Iran \\ ${ }_{5}^{5}$ Students Research Committee, School of Medicine, Arak University of Medical Sciences, Arak, IR Iran \\ 6 Students Research Committee, School of Medicine, Arak University of Medical Sciences, Arak, IR
6 Department of Radiology, School of Medicine, Arak University of Medical Sciences, Arak, IR Iran \\ *Corresponding author: Mojtaba Sharafkhah, Students' Research Committee, School of Medicine, Arak University of Medical Sciences, P. O. Box: 3819693345 , Arak, IR Iran. Tel: \\ +98-9119180298, Fax: +98-8633133193, E-mail: sharafkhah@arakmu.ac.ir
}

Received 2015 March 13; Accepted 2015 August 22

\begin{abstract}
Background: Nephrolithiasis in children is associated with a high rate of complications and recurrence.

Objectives:Since some evidences reported that zinc has an important place amongst inhibitors of crystallization and crystal growth, we decided to assess the effectiveness of oral zinc sulfate as adjuvant treatment in children with nephrolithiasis.

Patients and Methods: This was a randomized, double-blind, placebo-controlled clinical trial.102 children in the age range 1 month to 11 years with first nephrolithiasis were recruited. Patients were randomly divided into two equal groups (intervention and control groups). Intervention group received conservative measures for stones and $1 \mathrm{mg} / \mathrm{kg} / \mathrm{day}$ (maximum $20 \mathrm{mg} /$ day) oral zinc sulfate syrup for $3 \mathrm{months}$. Control group received placebo in addition to conservative measures, also for 3 months. Patients were followed up by ultrasonography for 9 months, in 5 steps (at the end of 1st, 2nd, 3rd, 6th and 9th month after treatment) assessing size and number of stones in the kidneys. Results: Only at the end of the first month, the average number (intervention: $1.15 \pm 3.78$, control: $1.3 \pm 2.84)(\mathrm{P}=0.001)$ and size (cm) (intervention: $0.51 \pm 1.76$, control: $0.62 \pm 1.39)(\mathrm{P}=0.001)$ of stones was significantly lower in the intervention group, and in other points there was no significant therapeutic efficacy in oral zinc adjuvant treatment compared to conservative treatment alone. Also, during the 9-month follow-up, the number and size of stones in both groups decreased significantly (both: $\mathrm{P}<0.0001$ ) in a way that the decrease in the intervention group showed no difference with the control group.

Conclusions: Adjuvant treatment with zinc is not more effective than consecutive treatment in children with nephrolithiasis. However, further studies are recommended due to the lack of clinical evidence in this field.
\end{abstract}

Keywords: Nephrolithiasis, Zinc Sulfate, Children

\section{Background}

Nephrolithiasis occurs due to a complex of environmental and genetic causes (1). According to studies, the prevalence of nephrolithiasis is increasing in different populations $(2,3)$ and this disorder can occur at any age. However, the prevalence of nephrolithiasis and urinary stones are lower in children than in adults and varies between $2 \%$ and $2.7 \%$ (4-6). In children, most stones are located in the kidneys and then in the ureters (7). Based on the evidence, prevalence of nephrolithiasis among children is low, though the disorder is always associated with a high rate of complications and recurrence (8). Overall, approximately $40 \%$ to $65 \%$ of calculi are composed of calcium oxalate and $14 \%$ to $30 \%$ of calcium phosphate (9, 10). Various theories have been proposed to explain the mechanism of stone formation and its growth. Based on one of the strongest theories, the formation and growth of stones is caused by supersaturation of ions in the urine. According to this theory, several factors such as the total volume of urine, concentration of calculi producing ions, concentration of stimulators and inhibitors of crystallization and the $\mathrm{pH}$ of urine are involved in the supersaturation (crystallization) and stone formation (11). Also factors such as metabolic disorders like hypercalciuria, hypocitraturia etc. and genitourinary abnormalities can predispose nephrolithiasis in children (12-14). Previous studies have shown that citrate, magnesium, pyrophosphate, certain glycosaminoglycans, nephrocalcin and phytates have inhibitory role in the formation of the most common urinary stones, namely calcium oxalate and calcium phosphate (11). In addition, recent evidence

Copyright (C) 2015, Growth \& Development Research Center. This is an open-access article distributed under the terms of the Creative Commons Attribution-NonCommercial 4.0 International License (http://creativecommons.org/licenses/by-nc/4.0/) which permits copy and redistribute the material just in noncommercial usages, provided the original work is properly cited. 
has shown the stimulatory or inhibitory role of some elements such as iron, copper and zinc in the formation and growth of urinary stones (15-17). Based on the hypothesis by Atakan et al. (17), four elements play a major role in the formation of each calculus. According to these authors, zinc and magnesium are involved in the formation of calcium oxalate stones as inhibitory factors and iron and copper as stimulatory factors. The role of zinc in the formation of urinary stones is still not completely identified $(15,18)$. However, based on some evidence, not only this element can be involved in the formation of kidney and urinary stones $(19,20)$, it can also have an inhibitory role in the formation and growth of stones in some cases (15, 17). Chi (16) used the fly model to look for genes which, when silenced, prevent or ameliorate kidney stones. In this study, 80 genes were examined and ultimately 10 genes which had a greater role in the formation of renal stones were identified. Results showed that these related genes and particularly genes related to zinc transport play an important role in the formation of kidney stones. Atakan et al. (17), concerning the inhibitory role of some elements in stone formation, showed that the mean levels of zinc and magnesium in the urine of healthy individuals are significantly greater than the stone patients.

\section{Objectives}

Considering the hypothesis of the role of elements in the formation and growth of calculi and the lack of clinical studies on the effects of zinc on kidney stones, we decided to assess the effectiveness of oral zinc sulfate as adjuvant treatment in children with nephrolithiasis.

\section{Patients and Methods}

\subsection{Study Population}

102 children, aged 1 month to 11 years with nephrolithiasis, who were followed in pediatric nephrology outpatient clinics in Amirkabir and Valiasr Hospital of Arak, Iran, in 2 years, were included in the study. Recruitment started on June 2010 and follow up ended in June 2013. Pediatric nephrolithiasis with clinical suspicion of renal stones based on clinical symptoms was diagnosed using KUB radiography (Kidney, Ureter, and Bladder X-ray) and renal and urinary tract ultrasonography. If these diagnostic procedures were negative with high suspicion, the occurrence or non-occurrence of stones was confirmed using unenhanced spiral CT scan of the abdomen and pelvis (21). Since the study of metabolic risk factors in children with renal stones is considered as one of the diagnostic measures for prevention of growth and recurrence of stones (22), the important serum and urine factors were assessed in each child for metabolic examination. Urinary factors were examined based on the normal age-appropriate values (21) (Table 1).

Initial evolution to check the inclusion and exclusion criteria included: age, sex, the number and size of the stones, growth and development status, family history of kidney and urinary tract stones, habitat, diet, birth weight, appetite status, history of congenital and acquired chronic diseases, history of recurrent infections, history of zinc deficiency. Based on these findings, the inclusion criteria were: 1) Children 1 month to 11 years old of both sexes, 2 ) children experiencing the first nephrolithiasis, 3) place of birth and living in city of Arak, Iran, 4) obtaining informed consent from the parents of children for participation in the study and appropriate compliance of parents for prescription of medication and referral to medical centers for monthly follow-up, 5) a balanced salt, protein, fat (as dietary factors involved in stone formation), milk, seafood, grains, cereals and vegetables (as food sources of zinc) intake according to age and daily need $(21,23)$. Our exclusion criteria were as cited in Box 1.

Since the measurement of serum levels of zinc is not a suitable criterion to estimate its levels in the body and is not recommended for routine screening $(23,24)$, to examine the children suspected of zinc deficiency, its clinical symptoms $(23,25)$ were saught. The stones larger than 5 $\mathrm{cm}$ and every stone of any size that caused obstruction in the kidneys and urinary tract were defined as indications for invasive treatment of stone (extracorporeal shock-wave lithotripsy (ESWL), percutaneous nephroscopy, etc.) (21). This study was confirmed by ethics committee of Arak University of Medical Sciences and in all stages of this study, we were committed to Helsinki declaration principles. Written consent was obtained from all of parents and they were free to leave the study at any time. This experiment is also registered as No. IRCT2012080710525N1 at www.irct.ir.

Table 1. Normal Urinary Factors in Metabolic Evaluation of Children With Urolithiasis

\begin{tabular}{|c|c|}
\hline Urine Constituent/Age & $\begin{array}{c}\text { Normal Values in } \\
\text { Random Urine Collection }\end{array}$ \\
\hline \multicolumn{2}{|l|}{ Calcium, mg/mg creat } \\
\hline $0-6$ mo & $<0.8$ \\
\hline 7-12 mo & $<0.6$ \\
\hline$\geq 2 y$ & $<0$ \\
\hline Oxalate, $\mathrm{mmol} / \mathrm{mmol}$ creat ${ }^{\mathrm{a}}$ & $0.15-0.26$ \\
\hline$<1 \mathrm{y}$ & $0.11-0.12$ \\
\hline $1 \leq 5 \mathrm{y}$ & $0.006-0.15$ \\
\hline \multicolumn{2}{|l|}{$5-12 y$} \\
\hline \multicolumn{2}{|l|}{ Uric acid, mg/dL GFR ${ }^{b}$} \\
\hline Term infant & 3.3 \\
\hline$>3 y$ & $<0.53$ \\
\hline \multicolumn{2}{|l|}{ Magnesium, mg/ mg creat } \\
\hline$>2 \mathrm{y}$ & $<0.12$ \\
\hline Citrate, mg/g creat & $>400$ \\
\hline Cystine, mg/g creat & $<75$ \\
\hline
\end{tabular}


Yousefichaijan P et al.

Box 1. Our Exclusion Criteria ${ }^{\mathrm{a}}$

Exclusion Criteria

1) Children with zinc deficiency or under prescription of zinc or recent zinc intake.

2) History of allergy to any form of zinc (syrup, tablet, capsule) or its intolerance.

3) Associated conditions and diseases with zinc deficiency including recent history of prolonged intravenous feeding, vegan diet, short bowel syndrome, URI, congenital metabolic disorders, wound healing, congenital or acquired GI abnormalities and intestinal surgery particularly in the duodenum and small intestine proximal (e.g., gastric bypass),celiac disease and other malabsorption syndromes, Crohn disease, cirrhosis, SCD, acrodermatitis enteropathica, malignancy, HIV/AIDS

4) Having any infections or chronic and acute febrile diseases with any sources in the body such as gastroenteritis, UTI, pneumonia, etc.

5) Chronic vomiting and diarrhea

6) Indications for aggressive stone treatment

7) Severe obesity (BMI over 99th percentile) ${ }^{b}$

8) Premature birth and birth weight less than 1,500 gr or VLBW

9) RF and structural abnormalities of the kidneys and urinary tracts

10) Family history of nephrolithiasis and/or urolithiasis

a Abbreviations: URI, Upper respiratory infection; GI, gastrointestinal; SCD, sickle cell disease; AIDS, human immunodeficiency virus infection / acquired immunodeficiency syndrome; UTI, urinary tract infection; VLBW, very low birth weight; RF, renal failure.

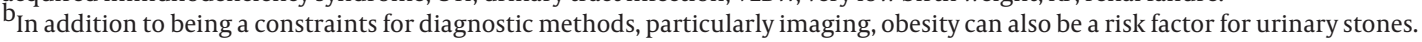

\subsection{Intervention}

This was a randomized, double-blind, placebo-controlled clinical trial study. The study coordination center at the Arak University Hospital (Amirkabir Hospital) randomly assigned participating patients to one of the two equal (Intervention and Control) groups. The random allocation sequence was generated by a computerized random number generator.

Intervention group received instructions regarding general conservative measures for urinary stones and 1 $\mathrm{mg} / \mathrm{kg} /$ day (maximum $20 \mathrm{mg} /$ day) oral zinc sulfate syrup for 3 months. The pediatric prophylactic dose of zinc (for gastroenteritis and other infections especially in the Middle East countries) is $20 \mathrm{mg} /$ day orally for 14 days (25). Since clinically a prophylactic trial of oral zinc $(1 \mathrm{mg} / \mathrm{kg} /$ day) is a safe and reasonable approach in situations in which deficiency is considered possible (24), we used this dose in our study.

General conservative measures included: adequate fluid intake (hydration with twice the maintenance fluid), sedative medications (if necessary), low sodium diet, thiazide diuretics, such as hydrochlorothiazide if these measures fail, potassium citrate with a dosage of 1 - $2 \mathrm{mEq} / \mathrm{kg} / 24$ hours, low sodium and oxalate diet in idiopathic hypercalciuria (IHC), (IHC is defined as a urine calcium to creatinine ratio of more than 0.2 in random urine samples (26)), some reduction in calcium intake or absent restriction of calcium and dairy (due to impaired child development), citrate supplementation in patients who have renal tubular acidosis or hypocitraturia, receive adequate dietary potassium, particularly if they are taking diuretics $(1,21)$. Control group in addition to gen- eral conservative measures, received placebo $(1 \mathrm{mg} / \mathrm{kg} /$ day) for 3 months. Both preparations [zinc sulfate syrup $(60 \mathrm{ml})$ and placebo $(60 \mathrm{ml})]$ were produced by the same company (Alhavi Company, Tehran, Iran) to ensure identical volume, consistency, shape and color. Also, both the zinc syrup and placebo were delivered to the parents in glass containers with lid of similar shape and size, without a name and with a code.

\subsection{Examinations and Follow-Up}

During 3 months of drug administration, parents were contacted at the end of each week (via phone or visited in person) to assess adherence to taking medications, possible side effects, any new infections and other conditions. By separating the randomization center (Amirkabir University Hospital) and examination site (Valiasr Hospital), participating patients and physicians assessing outcomes were blinded to the treatment allocation.

Although the side effects of zinc supplementation, such as nausea, vomiting, headache, vertigo, abdominal cramping, and diarrhea $(24,25)$, are rare considering the dosage used, we opted to record them during the study and warned parents about these symptoms and recommended to discontinue medication and notify treatment centers in case of observing any of the above symptoms after taking the prescribed medications. Parents of children were recalled for 5 steps of the abdomen and pelvis ultrasonography (at the end of 1st, 2nd, 3rd, 6th and 9th month after treatment) in examination site.

CT scan of the abdomen and pelvis is a method with 
ideal sensitivity and specificity for evaluation of renal stones in children; however, since the radiation exposure is high, we used ultrasonography (21). Both kidneys of patients were examined in 5 steps of ultrasonography and the number and size of the stones were recorded. Children who were excluded were replaced by other eligible children considering the initial inclusion and exclusion criteria and by same random allocation (computerized random number generator). Figure 1 illustrates the study recruitment process. The exclusion criteria during follow-up periods were: 1) Absence of cooperation or satisfaction for continuing the participation, 2) irregular use of medication, 3) zinc side effects, 4) having any new systemic disease and infection, 5) lack of access to patients. The following measures were carried out by not blinded physicians in randomization center: 1) Initial evaluation for selection of eligible patients, 2) necessary instructions to parents for daily administration of a teaspoon of med- ication (zinc and placebo) and conservative measures, 3) weekly follow-up, 4) replacing the patients excluded from the study. Abdomen and pelvis ultrasonography was conducted by one expert radiologist who was blind towards the treatment of children in examination site.

\subsection{Statistical Methods}

The collected data were analyzed with SPSS software (Statistical Package for the Social Sciences, version 18.0, SPSS Inc, Chicago, Ill, USA) and descriptive statistics methods for frequency determination. Mann-Whitney and Wilcoxon tests (due to non-normal distribution of the data) were used to comparison of ultrasonography results (number and stone size) in two groups and assess changes of number and stone size in each group during the 9 months of follow up, respectively. P-values less than 0.05 were considered significant.

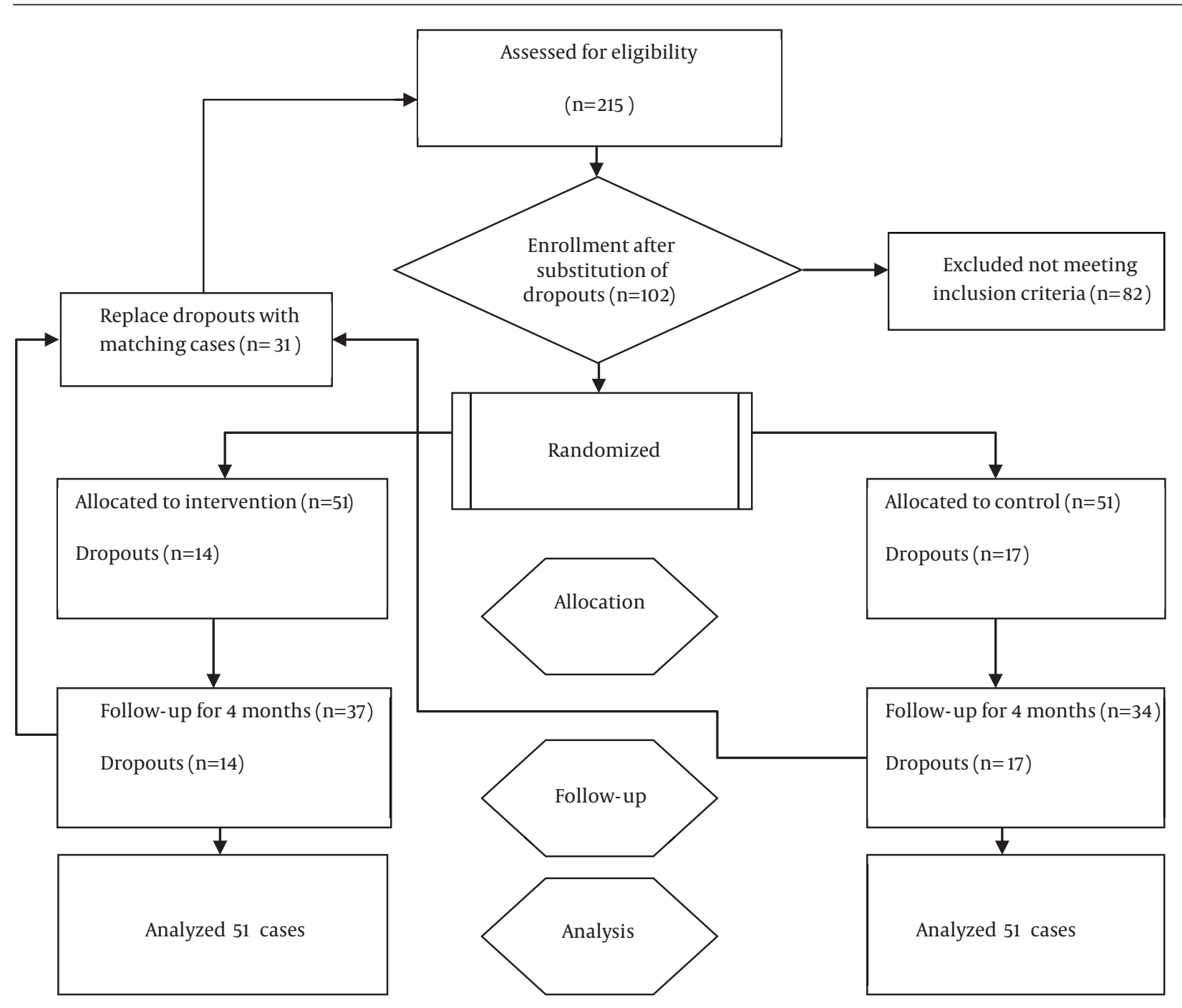

Figure 1. Randomization and Children's Flow Chart 


\section{Results}

In this 2 years lasting study, 215 children with nephrolithiasis were analyzed against the inclusion and exclusion criteria. We lost 31 patients to follow-up.

Among the $31(100 \%)$ children, who were excluded, 13 (41.9\%), 8 (25.8\%), 2 (6.4\%) and 8 (25.8\%) were excluded due to parental refusal to continue participation, irregular use of medication, zinc side effects [nausea in 1(50\%) and abdominal cramping in 1 (50\%) case] and new infection, respectively.

The mean age of patients was $5.36 \pm 2.3$ years with no significant difference between the two groups. The youngest child was 3 months and the oldest 11 years old. There were 25 (49\%) boys and 26 (50.9\%) girls in the intervention group and $32(62.7 \%)$ boys and 19 (37.2\%) girls in the control group $(\mathrm{P}=0.23)$.

The average size of the stones in both kidneys, in the first ultrasonography in the intervention group ( $0.51 \pm$ $1.76 \mathrm{~cm})$ compared to the control group $(0.62 \pm 1.39 \mathrm{~cm})$ $(\mathrm{P}=0.001)$ and in the second ultrasonography, in the control group $(0.46 \pm 0.59 \mathrm{~cm})$ compared to the intervention group $(0.52 \pm 0.92 \mathrm{~cm})(\mathrm{P}=0.001)$ was significantly lower and this difference in the third $(\mathrm{P}=0.43)$, fourth $(\mathrm{P}=0.43)$ and fifth $(\mathrm{P}=0.23)$ ultrasonography was not significant between the two groups (Table 2 ).

The number of stones in average, similar to the size, in the first ultrasonography $(\mathrm{P}=0.001)$ in the intervention group (1.15 \pm 3.78$)$ compared to the control group (1.3 \pm $2.84)$ and in the second ultrasonography $(P=0.001)$ in the control group $(1.06 \pm 1.29)$ compared to the intervention group (1.12 \pm 2.31 ) was significantly lower and this difference in the third $(\mathrm{P}=0.3)$, fourth $(\mathrm{P}=0.21)$ and fifth ( $\mathrm{P}$ $=0.28$ ) ultrasonography was not significant between the two groups (Table 3).

During the 9-month follow-up, the number and size of stones in both groups decreased significantly, but in a way that the decrease in the intervention group showed no difference with the control group. Figure 2 shows stone size and Figure 3 number of stones in the intervention and control group (both $\mathrm{P}<0.0001$ ).

Table 2. The Average Size of the Stones in 5 Sessions of Ultrasonography in Both Kidneys

\begin{tabular}{|c|c|c|c|}
\hline \multirow[t]{2}{*}{ Months } & \multicolumn{2}{|c|}{ Stone Size, $\mathrm{cm}^{\mathrm{a}}$} & \multirow[t]{2}{*}{ P-Value $^{b}$} \\
\hline & Intervention $\mathrm{c}$ & Control $^{d}$ & \\
\hline First & $0.51 \pm 1.76$ & $0.62 \pm 1.39$ & 0.001 \\
\hline Second & $0.52 \pm 0.92$ & $0.46 \pm 0.59$ & 0.001 \\
\hline Third & $0.3 \pm 0.16$ & $0.31 \pm 0.21$ & 0.43 \\
\hline Sixth & $0.19 \pm 0.06$ & $0.18 \pm 0.09$ & 0.43 \\
\hline Ninth & $0.12 \pm 0.04$ & $0.15 \pm 0.07$ & 0.23 \\
\hline $\begin{array}{l}\mathrm{a}_{\text {Data are }} \mathrm{p} \\
\mathrm{b}_{\mathrm{P} \text {-value le }} \\
\mathrm{c}_{\text {The group }} \\
\mathrm{d}_{\text {The group }}\end{array}$ & $\begin{array}{l}\text { as mean } \pm \text { SD. } \\
05 \text { was considered } \\
\text { oral zinc and cons } \\
\text { conservative treat }\end{array}$ & $\begin{array}{l}\text { snificant. } \\
\text { vative treatmen } \\
\text { ent alone. }\end{array}$ & \\
\hline
\end{tabular}

Table 3. The Average Number of the Stones in 5 Sessions of Ultrasonography in Both Kidneys

\begin{tabular}{lccc}
\hline \multirow{2}{*}{ Months } & \multicolumn{2}{c}{ Stone Size $^{\mathbf{a}}$} & \multirow{2}{*}{ P-Value $^{\mathbf{b}}$} \\
\cline { 2 - 3 } & Intervention $^{\mathbf{c}}$ & Control $^{\mathbf{d}}$ & \\
\hline First & $1.15 \pm 3.78$ & $1.3 \pm 2.84$ & 0.001 \\
Second & $1.12 \pm 2.31$ & $1.06 \pm 1.29$ & 0.001 \\
Third & $0.76 \pm 0.44$ & $0.85 \pm 0.6$ & 0.3 \\
Sixth & $0.5 \pm 0.15$ & $0.6 \pm 0.29$ & 0.21 \\
Ninth & $0.32 \pm 0.11$ & $0.4 \pm 0.19$ & 0.28 \\
\hline
\end{tabular}

${ }^{\mathrm{a}}$ Data are presented as mean $\pm \mathrm{SD}$.

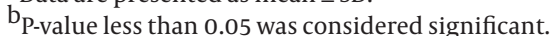

${ }^{\mathrm{C}}$ The group received oral zinc and conservative treatment.

$\mathrm{d}_{\text {The group received conservative treatment alone. }}$

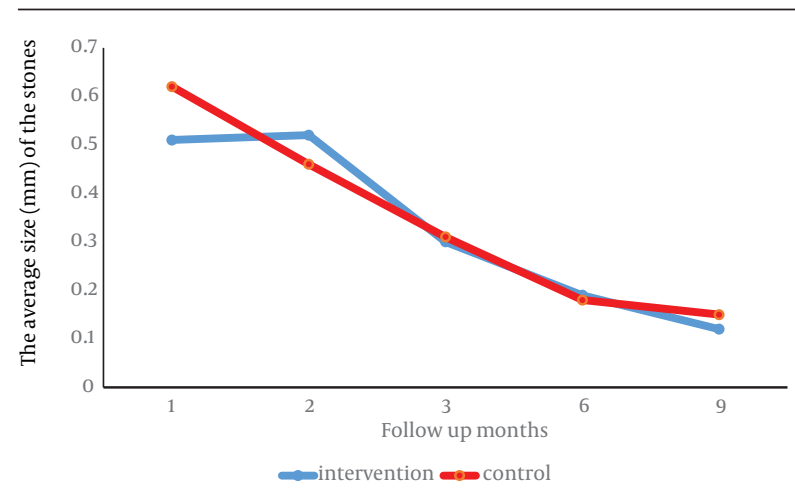

Figure 2. The Average Size (cm) of the Stones in 5 Steps of Follow Up Period

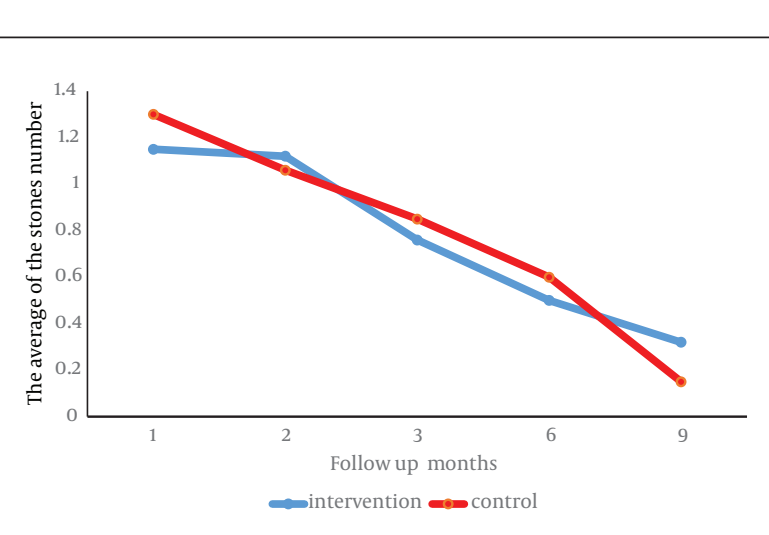

Figure 3. The Average Number of the Stones in 5 Steps of Follow Up Period

\section{Discussion}

The purpose of our study was to investigate the clinical role of oral zinc as adjuvant treatment in children with nephrolithiasis. Based on our results, the number and size of stones was significantly lower in the intervention group compared to the control group only at the end of the first month after beginning of treatment. In the rest of the follow up sessions, there was no significant differ- 
ence between the two groups. Also, our 9-month followup results showed that adjuvant treatment with zinc is not more effective than conventional treatment of nephrolithiasis in children.

According to some authors, presence of some elements in the core of the calculus rather than its outer layer indicates their role in stimulation or inhibition of the formation of calculus $(27,28)$.

Bazin et al. (29), in 2007 studied heavy elements in the urinary stones using micro fluorescence $\mathrm{X}$ analysis with synchrotron radiation. They showed that the content of zinc in some urinary stones (such as calcium stones) are almost 15 times more than that in other stones. These findings were also obtained in similar studies by Hesse et al. (30), Levinson et al. (31) and Joost and Tessadri (32).

In contrary, Sutor (33) and Grases et al. (34) showed that zinc and aluminum in low concentrations could have an inhibitory role in the formation of calcium oxalate stones. Based on these findings and animal study by T Chi (16), it appears that zinc has a role in the formation of urinary stones $(15,29)$. However, according to some authors $(15,18,20)$, the stimulatory or inhibitory role of zinc in the formation of urinary stones is still unclear.

Based on this unclear role, laboratory studies have been conducted to determine indirectly the role of zinc in renal stones. Atakan et al. (17) in 2007, investigated the urinary levels of zinc, iron, magnesium and copper in 104 patients with calcium oxalate stones and 77 control subjects. The results of this study showed that urinary and serum levels of zinc in healthy individuals were significantly higher than those of patients. Komleh et al.(19) did not find any significant difference in serum zinc levels between stone formers and normal subjects. However, they showed that urinary excretion of zinc in healthy subjects was significantly higher than in patients.

Contrary to Atakan (17) and Komleh et al. (19), Trinchieri et al. (18) in a study on 104 stone formers compared with the control group showed that the urinary excretion of glycosaminoglycan and zinc was higher in stone formers. Based on the study by Cohanim et al. (35), secretion of zinc in men with renal stones was significantly higher than in normal men. In a study by Ozgurtas et al. (20) in 2004, urinary zinc and copper were measured in 27 healthy controls and 30 calcium oxalate stone formers. Based on this study, secretion of zinc in stone formers was significantly higher than in the control group.

As a conclusion, although based on our results zinc cannot have a considerable clinical impact on the treatment of urinary stones in children with nephrolithiasis, future clinical studies on evaluation of the impact of zinc on urinary stones is recommended due to the severe shortage of clinical studies and the following 3 reasons: 1 ) various evidence indicates the role of elements such as zinc in the formation of urinary stones $(15,16,18-20), 2)$ there are controversies between the results of laboratory studies conducted on the role of zinc in the formation of urinary stones, 3) showing higher or lower serum and/or urinary levels of zinc in stone formers compared to healthy controls in laboratory studies cannot be a valid reason for the clinical role of zinc in urinary stones.

The limitation of our study was that parents did not cooperate since the follow-up lasted for long. Although some of the samples were lost during our study due to this problem, it was tried to eliminate this limitation by explaining to the parents that as an inexpensive supplement with no side effects, oral zinc may be helpful in the treatment of their child. Furthermore, we did not measure the level of urinary zinc in our study. Since the measurement of urinary zinc can be helpful in strengthening the conclusion whether zinc is effective or ineffective in a clinical trial study, it is suggested that future clinical studies be conducted with regard to this issue.

In current study, the effect of the type of urinary stones in clinical response to zinc was not considered. Given the possible difference between the roles of elements in some stones compared to other stones, it is of great importance to consider this point in future studies.

\section{Acknowledgments}

The research team wishes to thank vice chancellor of research for the financial support and also children and their parents who contributed to this research.

\section{Footnote}

Funding/Support:This study was financially supported by Arak University of Medical Sciences. IRCT No. $2012080710525 \mathrm{~N} 1$.

\section{References}

1. Naseri M, Varasteh AR, Alamdaran SA. Metabolic factors associated with urinary calculi in children. Iran J Kidney Dis. 2010;4(1):32-8. [PubMed: 20081302]

2. Edvardsson V, Elidottir H, Indridason OS, Palsson R. High incidence of kidney stones in Icelandic children. Pediatric Nephrol. 2005;20(7):940-4. doi: 10.1007/s00467-005-1861-5.

3. Naseri M, Sadeghi R. Role of high-dose hydrochlorothiazide in idiopathic hypercalciuric urolithiasis of childhood. Iran J Kidney Dis. 2011;5(3):162-8. [PubMed: 21525575]

4. Vahlensieck EW, Bach D, Hesse A. Incidence, prevalence and mortality of urolithiasis in the German Federal Republic. Urol Res. 1982;10(4). doi:10.1007/bfo0255937.

5. Borghi L, Ferretti PP, Elia GF, Amato F, Melloni E, Trapassi MR, et al. Epidemiological Study of Urinary Tract Stones in a Northern Italian City. BrJUrol.1990;65(3):231-5. doi:10.1111/j.1464-410X.1990. tb14716.x. [PubMed: 2337741]

6. Erbagci A, Erbagci AB, Yilmaz M, Yagci F, Tarakcioglu M, Yurtseven C, et al. Pediatric Urolithiasis. Scandinavian J Urol Nephrol. 2003;37(2):129-33. doi:10.1080/00365590310008866.

7. Gearhart JP, Herzberg GZ, Jeffs RD. Childhood uro lithiasis: experiences and advances. Pediatrics . 1991;87:445-50. [PubMed: 2011420]

8. Noe HN, Stapleton FB, Jerkins GR, Roy S. Clinical experience with pediatric urolithiasis. JUrol . 1983;129:1166-8. [PubMed: 6854792]

9. Milliner DS, Murphy ME. Urolithiasis in Pediatric Patients Mayo Clinic Proceedings. 1993;68(3):241-8. doi: 10.1016/s00256196(12)60043-3. [PubMed: 8474265]

10. McKay CP. Renal Stone Disease. Pediatr Rev. 2010;31(5):179-88. doi 10.1542/pir.31-5-179. [PubMed: 20435709]

11. Copelovitch L. Urolithiasis in Children. Pediatr Clin North Am. 
2012;59(4):881-96. doi: 10.1016/j.pcl.2012.05.009. [PubMed: 22857835]

12. Peres LAB, Langer SS, Schmidt RC, Nacke RAB, Francescon PVM, Almeida RCD, et al. Nefrolitíase em pacientes pediátricos: investigação metabólica e anatômica. J Brasileiro de Nefrologia. 2011;33(1):50-4. doi:10.1590/s0101-28002011000100007.

13. VanDervoort K, Wiesen J, Frank R, Vento S, Crosby V, Chandra M, et al. Urolithiasis in Pediatric Patients: A Single Center Study of Incidence, Clinical Presentation and Outcome. J Urol. 2007;177(6):2300-5. doi: 10.1016/j.juro.2007.02.002. [PubMed: $17509344]$

14. Coward RJ, Peters CJ, Duffy PG, Corry D, Kellett MJ, Choong S, et al. Epidemiology of paediatric renal stone disease in the UK. Arch Dis Child. 2003;88(11):962-5. [PubMed:14612355]

15. Rangnekar GV, Gaur MS. Serum and Urinary Zinc Levels in Urolithiasis. Br J Urol. 1993;71(5):527-9. doi:10.1111/j.1464-410X.1993. tb16019.x. [PubMed: 8518857]

16. Chi T. Research identifies important role of zinc in kidney stone. Paper presented at the Genetics Society of America's 54th Annual Drosophila Conference.; Washington, DC. 2013.

17. Atakan IH, Kaplan M, Seren G, Aktoz T, Gül H, Inci O. Serum, urinary and stone zinc, iron, magnesium and copper levels in idiopathic calcium oxalate stone patients. Int Urol Nephrol. 2007;39(2):351-6. doi: 10.1007/s11255-006-9050-4. [PubMed: 17203355]

18. Trinchieri A, Mandressi A, Luongo P, Rovera F, Longo G. Urinary Excretion of Citrate, Glycosaminoglycans, Magnesium and Zinc in Relation to Age and Sex in Normal Subjects and in Patients who form Calcium Stones. Scandinavian J Urol Nephrol. 1992;26(4):379-86. doi:10.3109/00365599209181230.

19. Komleh K, Hada P, Pendse AK, Singh PP. Zine, copper and manganese in serum, urine and stones. Int Urol Nephrol. 1990;22(2):113-8. doi:10.1007/bfo2549826. [PubMed: 2354889]

20. Ozgurtas T, Yakut G, Gulec M, Serdar M, Kutluay T. Role of Urinary Zinc and Copper on Calcium Oxalate Stone Formation. Urologia Int. 2004;72(3):233-6. doi: 10.1159/000077122.

21. Elder JS. Urinary Lithiasis. In: Kleigman RM, Behrman RE, Jenson HB, Stanton BP, editors. Nelson Text Book of Pediatrics. Philadelphia: Saunders Elsevier; 2011. pp. 1864-1864.e8.

22. Spivacow FR, Negri AL, del Valle EE, Calviño I, Fradinger E, Zanchetta JR. Metabolic risk factors in children with kidney stone disease. Pediatr Nephrol. 2008;23(7):1129-33. doi: 10.1007| s00467-008-0769-2. [PubMed: 18324422]

23. Saper RB, Rash R. Zinc: an essential micronutrient. Am Fam Physician. 2009;79(9):768-72. [PubMed: 20141096]

24. Krebs NF, Primak LE. Pediatric nutrition and nutritional disorders. In: Kliegman R. M., Stanton B. F., Geme III J. W., Schor N. F., Behrman R. E., editors. Nelson Essentials of Pediatrics. Philadelphia: Saunders; 2010.

25. Greenbaum LA. Micronutrient Mineral Deficiencies. 2011:211-211. e3. doi:10.1016/b978-1-4377-0755-7.00051-8.

26. Yousefi P, Firouzifar M, Cyrus A. Does hydrochlorothiazide prevent recurrent urinary tract infection in children with idiopathic hypercalciuria? J Pediatr Urol. 2013;9(6):775-8. doi: 10.1016/j. jpurol.2012.09.008. [PubMed: 23131530]

27. Durak I, Kilic Z, Sahin A, Akpoyraz M. Analysis of calcium, iron, copper and zinc contents of nucleus and crust parts of urinary calculi. Urol Res. 1992;20(1):23-6. doi: 10.1007/bfo0294330. [PubMed:1736483]

28. Perk H, Serel T, Ko. scedil. ar A, Deniz N, et al. Analysis of the Trace Element Contents of Inner Nucleus and Outer Crust Parts of Urinary Calculi. Urologia Internationalis. 2002;68(4):286-90. doi: 10.1159/000058452. [PubMed: 12053034]

29. Bazin D, Chevallier P, Matzen G, Jungers P, Daudon M. Heavy elements in urinary stones. Urol Res. 2007;35(4):179-84. doi:10.1007| s00240-007-0099-z. [PubMed:17492279]

30. Hesse A, Dietze HJ, Berg W, Hienzsch E. Mass spectrometric trace element analysis of calcium oxalate uroliths. Eur Urol .1977;3:359-61. [PubMed: 604069]

31. Levinson AA, Nosal M, Davidman M. Trace elements in kidney stones from three areas in the United States. Invest Urol. 1978;15:270-4. [PubMed: 627468]

32. Joost J, Tessadri R. Trace element investigations in kidney stone patients. Eur Urol. 1987;13(4):264-70. [PubMed:3653168]

33. Sutor D. Growth Studies of Calcium Oxalate in the Presence of Various Ions and Compounds. Br J Urol. 1969;41(2):171-8. doi: 10.1111/j.1464-410X.1969.tb09919.x. [PubMed: 4305899]

34. Grases F, Genestar C, Millán A. The influence of some metallic ions and their complexes on the kinetics of crystal growth of calcium oxalate. J Crystal Growth. 1989;94(2):507-12. doi: 10.1016/0022-0248(89)90028-6.

35. Cohanim M, Yendt ER. The effects of thiazides on serum and urinary zinc in patients with renal calculi. Johns Hopkins Med J. 1975;136(3):137-41. [PubMed: 804069] 